\title{
A comparative discussion of incisional methods in total capsulectomy of the breast
}

Tae Hyung Kim ${ }^{1}$, Seok Min Yoon ${ }^{1}$, Syeo Young Wee ${ }^{1}$, Hyok Sue $\mathrm{Oh}^{2}$, Hyun Gyo Jeong ${ }^{1}$

${ }^{1}$ Department of Plastic and Reconstructive Surgery, Soonchunhyang University College of Medicine, Gumi; ${ }^{2}$ W Plastic Surgery, Seoul, Korea
This work was supported in part by the Soonchunhyang University Research Fund.
Background Capsular contracture is a frequent complication of breast augmentation that constitutes one of the most common reasons for secondary operations. Capsular contracture is treated surgically, often with total capsulectomy. Therefore, in this study, we aimed to study correlations among intraoperative observations, physical examination findings, and characteristics of the previous operation in patients with capsular contracture who underwent total capsulectomy.

Methods A retrospective chart review was conducted for patients treated from May 2017 to April 2019, analyzing 24 breasts in 12 female patients. The patients were classified in terms of the Baker grade, incision type, implant type, and implant plane. During the operation, we evaluated the ease of dissection based on intraoperative features such as anterior and posterior wall dissection, bleeding tendency, and scar length. Statistical analysis was performed to identify association between variables

Results The implant was changed in eight patients, while only explantation was performed in the remaining four patients. The ease of capsule dissection had a proportional correlation with the Baker grade $(\mathrm{P}=0.005)$. Intraoperative dissection was significantly easier in the inframammary fold (IMF) group than in the periareolar group ( $P=0.035)$. Conclusions An IMF incision is preferable for planning en bloc capsulectomy. However, for aesthetic concerns, a periareolar incision would be preferable. In addition, a lower Baker grade (grade I or II) was associated with easier dissection. Therefore, surgeons should choose the incision type depending on the necessity of performing en bloc capsulectomy, Baker grade, and scar length.

Keywords Breast / Contracture / Reoperation

\section{INTRODUCTION}

Capsular contracture is a commonly encountered complication after breast augmentation [1] that has been reported to occur in $2.8 \%-$ $15.9 \%$ of patients [1-4]. Although its pathophysiology has not been

Received: Apr 27, 2021 Revised: Jul 3, 2021 Accepted: Sep 29, 2021

Correspondence: Hyun Gyo Jeong Department of Plastic and Reconstructive Surgery, Soonchunhyang University College of Medicine, 179 1(il)gongdanro, Gumi 39371, Korea

Tel: +82-54-468-9150, Fax: +82-54-463-7504, E-mail: 33044@schmc.ac.kr

Copyright @ 2021 The Korean Society for Aesthetic Plastic Surgery.

This is an Open Access article distributed under the terms of the Creative Commons Attribution Non-Commercial License (https://creativecommons.org/licenses/by-nc/4.0/) which permits unrestricted non-commercial use, distribution, and reproduction in any medium, provided the original work is properly cited. www.e-aaps.org fully elucidated, multifactorial causes, such as infection, fluid collection (e.g., hematoma), radiation therapy, and foreign body reaction have been suggested [5-11]. Aspects of the implant design (e.g., saline or silicone gel and textured or smooth) have also been reported as causes of capsular contracture [12-14]. In addition, breast implant-associated anaplastic large cell lymphoma (BIA-AL$\mathrm{CL}$ ) has been reported in countries worldwide, and two cases have recently been reported in Korea. Seroma fluid is one of the main symptoms of BIA-ALCL, and it may also cause capsular contracture unless it is managed properly [5-11].

Various methods have been proposed to treat capsular contracture, and whether capsulotomy or capsulectomy is better for the treatment of capsular contracture has been a topic of discussion. Numerous surgical techniques have been modified, and prior studies have considered the possibility of changing the plane and re- 
placing the implant with tissue flaps [15-17].

Capsular contracture classified as Baker grade III or IV is usually treated surgically. The gold standard treatment for this complication has been considered capsulectomy with or without capsulotomy [18]. Multiple operations have been suggested when capsulotomy alone is performed because contracture is likely to recur [19]. The most common and effective surgical treatment has been reported to be total capsulectomy [20].

As breast augmentation is becoming more common, the number of patients requiring reoperation is also increasing proportionally, and many patients with capsular contracture and BIA-ALCL prefer total capsulectomy $[12,13]$.

Previous studies on capsular contracture mainly studied the types of procedures performed, the need for reoperation, and what should be noted during the initial operation to reduce the incidence of capsular contracture based on its pathophysiology. However, no study has yet focused on the intraoperative findings of total capsulectomy, which is considered to be the most effective treatment for capsular contracture.

Therefore, we aimed to investigate differences in the intraoperative findings in total breast capsulectomy during reoperation according to factors including the location of the previous incision and the pocket where the implant was located. We also discuss the advantages and disadvantages of certain incision positions during reoperation.

\section{METHODS}

A retrospective chart review was conducted from May 2017 to April 2019 to identify patients who underwent total capsulectomy performed by a single surgeon. The institutional review board approved this study, which included 24 breasts in 12 female patients.

During the initial physical examination, we evaluated the degree of capsular contracture in all patients using the Baker grading system. According to the Baker grading system, grade I is contracture that is soft and natural in size and shape, grade II refers to contracture with a slightly firm texture, grade III is contracture with an abnormal shape, and grade IV refers to cases with a hard texture, an abnormal shape, and pain [21]. The incision site used in the previous surgery was checked in advance, along with the location of pocket and the type and volume of the inserted implant.

A designated surgeon planned the reoperation as total capsulectomy with implant change, explored the capsule of each patient, and decided whether it was necessary to change the implant. If the implant was textured, it was changed to a smooth one; otherwise, the surgeon decided whether to change the implant based on intraoperative findings, such as adhesion, discharge, any other infectious signs, and patients' requests.

The approach during the second operation was decided based on the surgeon, prioritizing easy accessibility and low bleeding ten- dency. Acellular dermal matrix was used depending on the intraoperative findings, such as a thin skin flap and patient-related factors such as allergy to preservatives. Periareolar incisions were made through the outer edges of the areola. The pectoralis major muscle was indicated for the upper pole, and the suture mark for fixation of the acellular dermal matrix was indicated to be along the inframammary fold (IMF). Acellular dermal matrix was designed and trimmed to fit into the breast pocket when patients consented to its use.

The senior authors (HSO and HGJ) evaluated the ease of dissection according to the capsule location using a 4-point classification ( 1 =poor, $2=$ mild, $3=$ good, and $4=$ excellent $)$ and in terms of adhesion, bleeding tendency, the visual field, and operation time. Bleeding tendency was also categorized using a 4-point classification, as follows: $1=$ low bleeding ( $<2$ pieces of surgical gauze), $2=$ mild bleeding $(<4$ pieces of surgical gauze $), 3=$ moderate bleeding ( $<6$ pieces of surgical gauze), and $4=$ severe bleeding $(~ \geq 6$ pieces of surgical gauze). A visual analogue scale was used to estimate blood loss [22]. We further checked the possibility of en bloc capsulectomy. After surgery, the scar length was measured and compared according to each incision site.

For most variables in this study, mean values were compared using the Mann-Whitney U test because the sample size was small. Pearson correlation coefficients were used to estimate relationships between two sets of data. Statistical analyses were performed using SPSS version 27.0 (IBM Corp., Armonk, NY, USA).

\section{RESULTS}

Eight patients underwent total capsulectomy with implant reinsertion and four patients underwent only total capsulectomy. The mean age of patients was $37.9 \pm 7.5$ years, and the mean follow-up period was $12.3 \pm 1.3$ months. Table 1 shows the patients' age, location of the previous incision, location of the incision during reoperation, and the pocket and type of implant insertion.

The average age of patients in the reoperation group was $40.1 \pm 8$ years. The mean implant volume was $268.1 \pm 21.1 \mathrm{cc}$. Among the patients in the reoperation group, three underwent IMF incisions, three underwent axillary incisions, and two underwent periareolar incisions, as in the previous operation. In this group, implants were placed in the subglandular space in three patients and in the subpectoral space in five patients in the previous surgery. A smooth implant was used in one patient, a textured round implant in five patients, and a tear-drop implant in two patients. During the reoperation, six patients received IMF incisions and the remaining two had periareolar incisions.

The average age of the patients who underwent only total capsulectomy was $33.5 \pm 4.4$ years. In all four patients, axillary incision was performed in the previous operation. The implants inserted during the previous surgery were located in the subpectoral space 


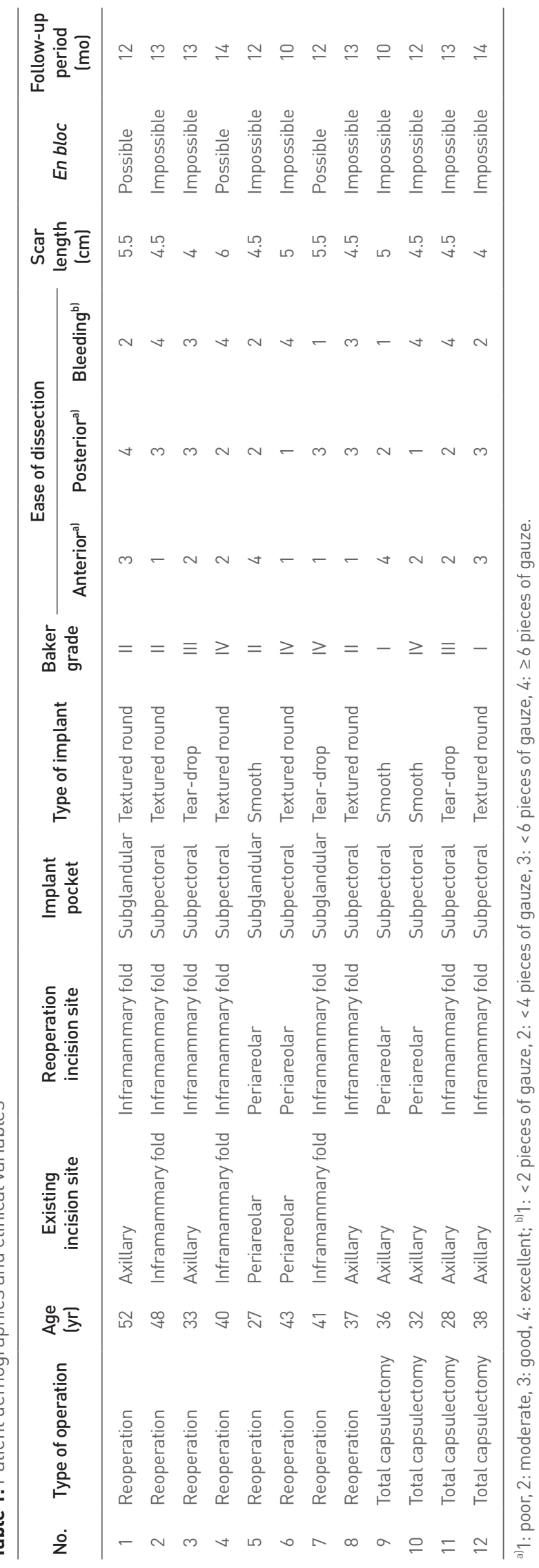

in all four patients. Smooth implants were used in two patients, a textured round implant was used in one patient, and a tear-drop implant was used in one patient. During the exploration, two patients received IMF incisions and the remaining two received peri-
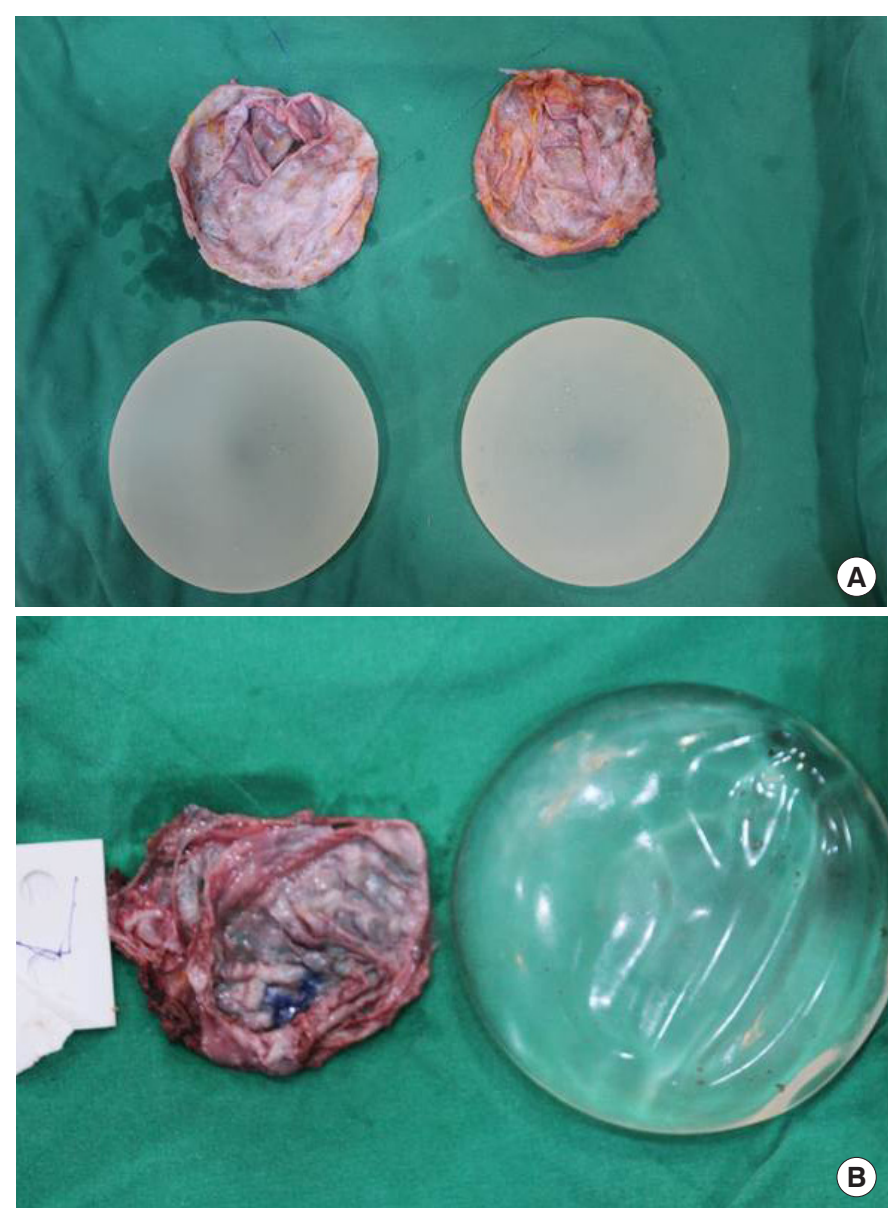

Fig. 1. Cases of removing the implant and the capsule separately (A, B).

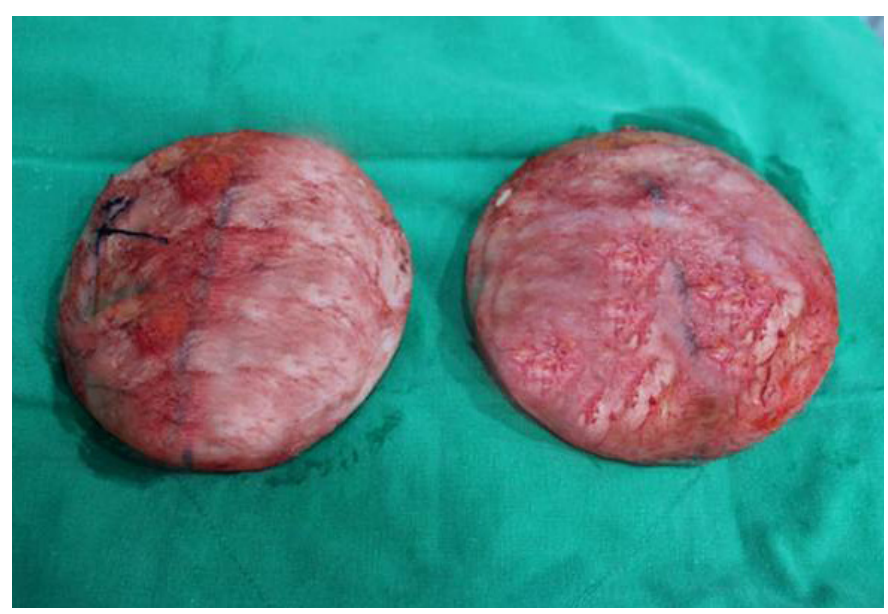

Fig. 2. Cases of en bloc capsulectomy. 
areolar incisions.

Information on the difficulty of detachment, scar length, possibility of en bloc removal, and degree of bleeding is summarized in Table 1. In the reoperation group, en bloc capsulectomy (Fig. 1) was possible in three patients, whereas in the exploration group, it was not possible in any of the four patients; instead, total capsulectomy

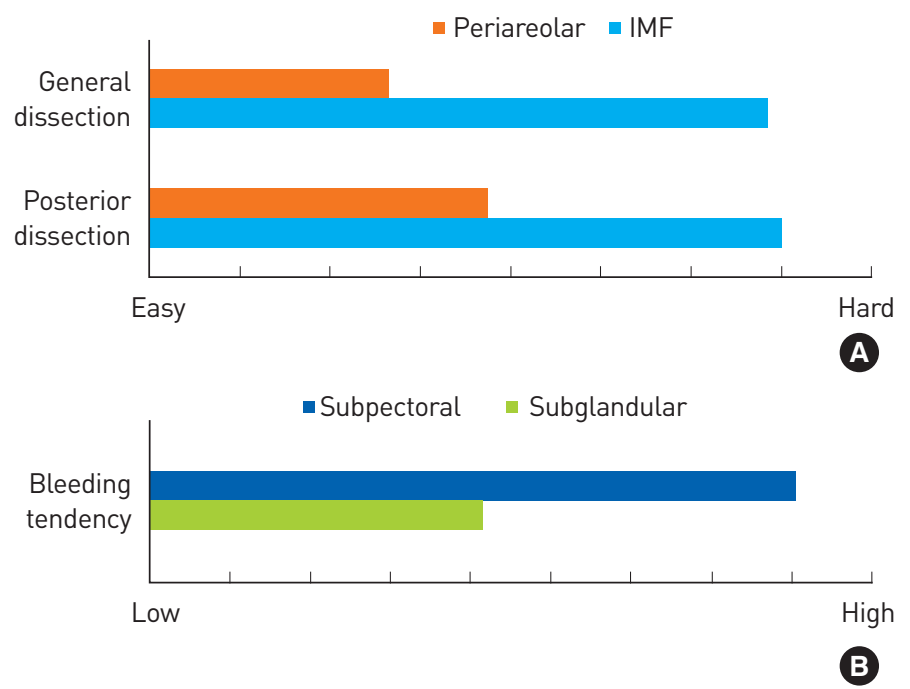

Fig. 3. Diagrams comparing the ease of dissection according to the incision type and implant pocket. (A) Difficulties of dissection in general and in the posterior wall. (B) Bleeding tendency depending on the type of plane. IMF, inframammary fold.
(Fig. 2) was performed in which the anterior and posterior capsules were excised separately.

Although the IMF and periareolar groups had no significant differences in terms of the ease of anterior capsule dissection, there were significant differences in the ease of posterior capsule dissection ( $\mathrm{P}=0.011)$ and general capsule dissection $(\mathrm{P}=0.001)$ (Fig. 3 ). Furthermore, patients in whom the implant was located in the subglandular space had a significantly lesser degree of bleeding than

Table 2. Comparison of each incision type

\begin{tabular}{lccc}
\hline Type & Periareolar group & IMF group & P-value $^{\text {a) }}$ \\
\hline Implant pocket & 1 & 2 & 1.000 \\
Subglandular & 3 & 6 & \\
Subpectoral & & & 0.869 \\
Baker grade & 1 & 1 & \\
Grade I & 1 & 3 & \\
Grade II & 0 & 2 & \\
Grade III & 2 & 2 & \\
Grade IV & & 5 & \\
Capsulectomy technique & 4 & 3 & \\
Total & 0 & $4.81 \pm 0.75$ & 0.035 \\
En bloc & $4.75 \pm 0.29$ & 5 & \\
Scar length (cm), mean \pm SD & & &
\end{tabular}

IMF, inframammary fold.

a) Statistically significant when $\mathrm{P}<0.05$.
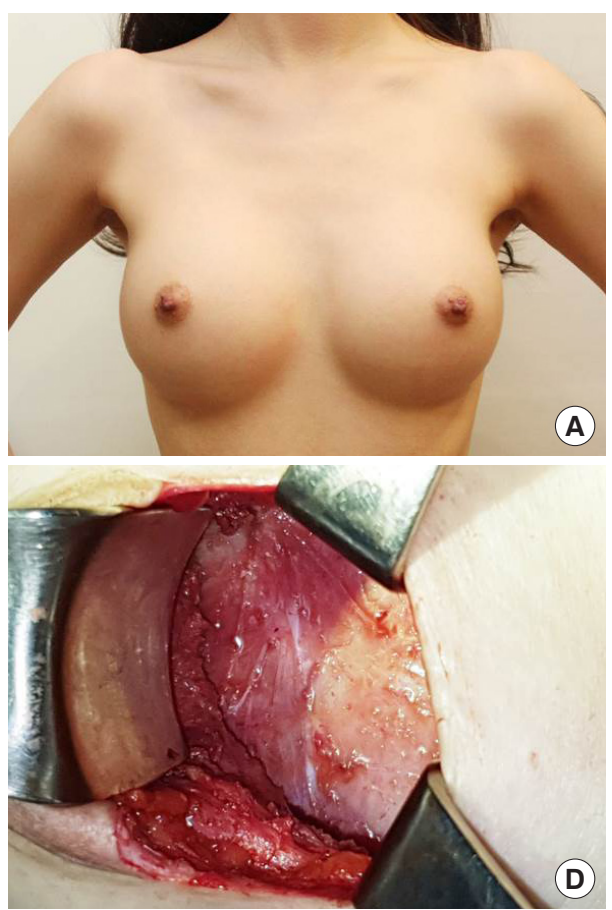
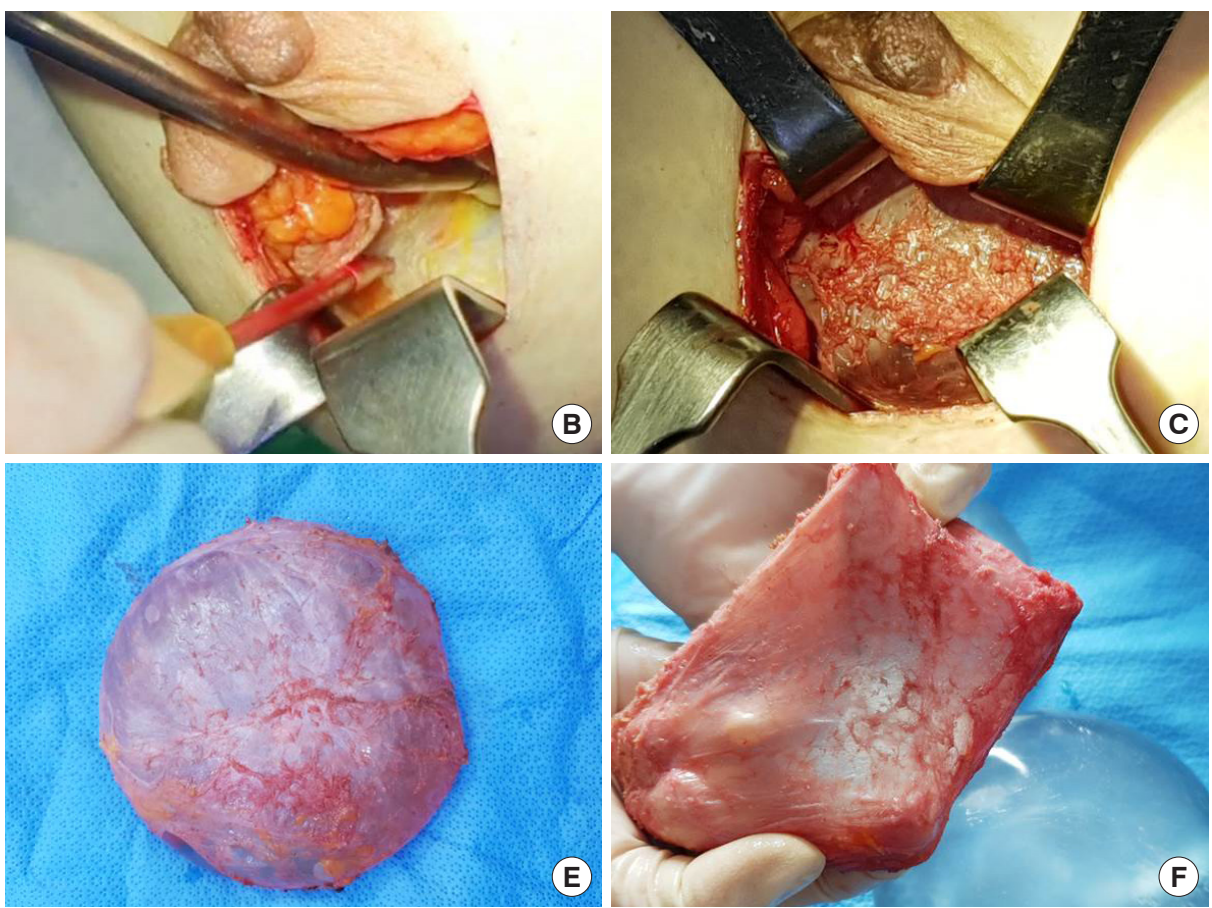

Fig. 4. A case involving a peri-areolar incision. (A) Initial photograph. (B) Intraoperative photograph; the anterior capsule was dissected. (C-E) A thin capsule was identified without any calcifications and the implant was intact. (F) The thin posterior capsule was identified. 
those in whom the implant was located in the subpectoral space. The average scar length was $4.94 \pm 0.68 \mathrm{~cm}$ in the reoperation group and $4.5 \pm 0.41 \mathrm{~cm}$ in the explantation group. The incision length was slightly but significantly longer in patients who received IMF incisions $(4.81 \pm 0.75 \mathrm{~cm})$ than in those who received periareolar incisions $(4.75 \pm 0.29 \mathrm{~cm})(\mathrm{P}=0.035)$ (Table 2). The ease of dissec-
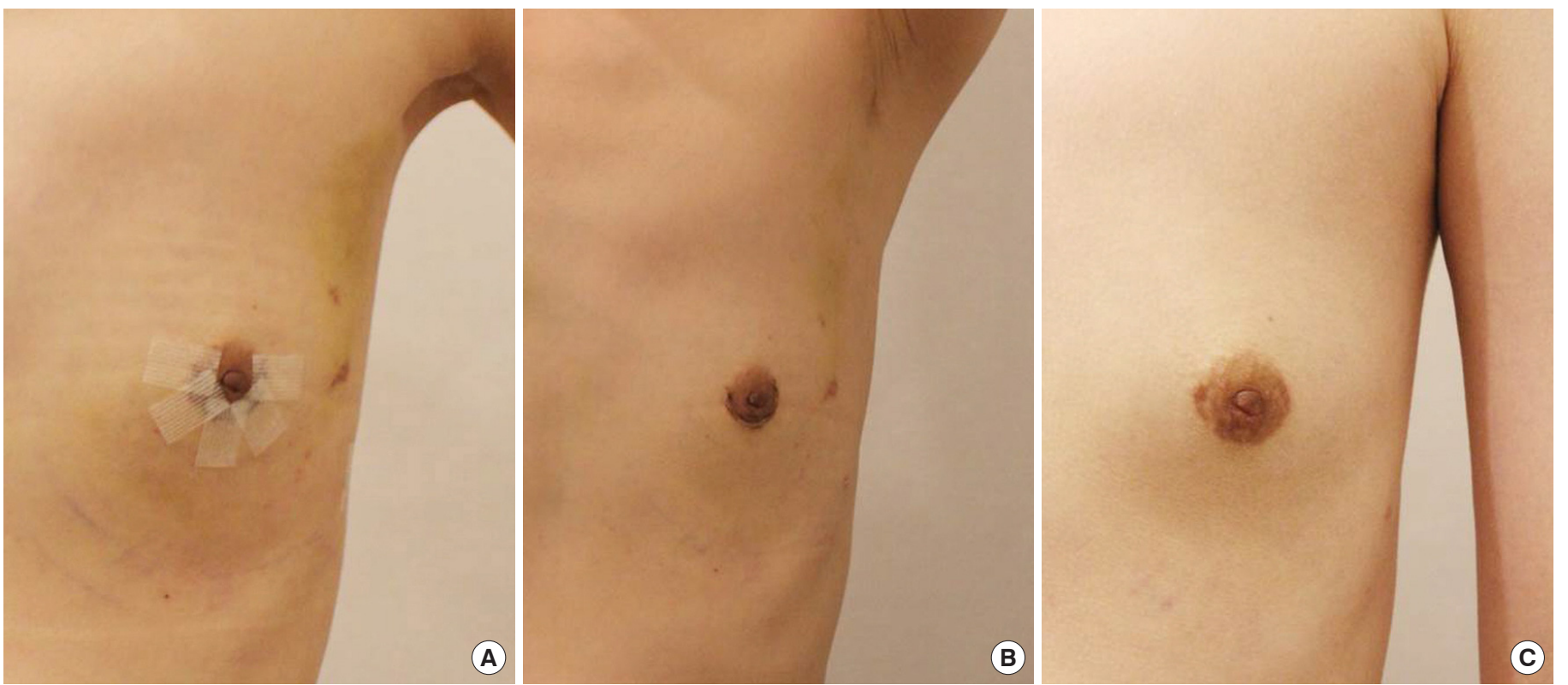

Fig. 5. Follow-up photographs of a patient who received a periareolar incision. (A) Four days after the operation. (B) One month after the operation. (C) Two months after the operation.
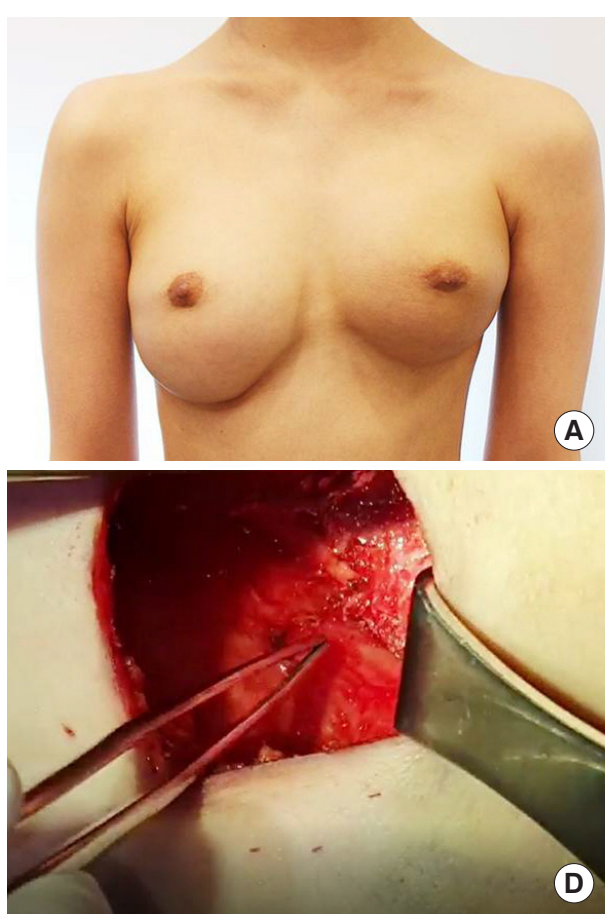
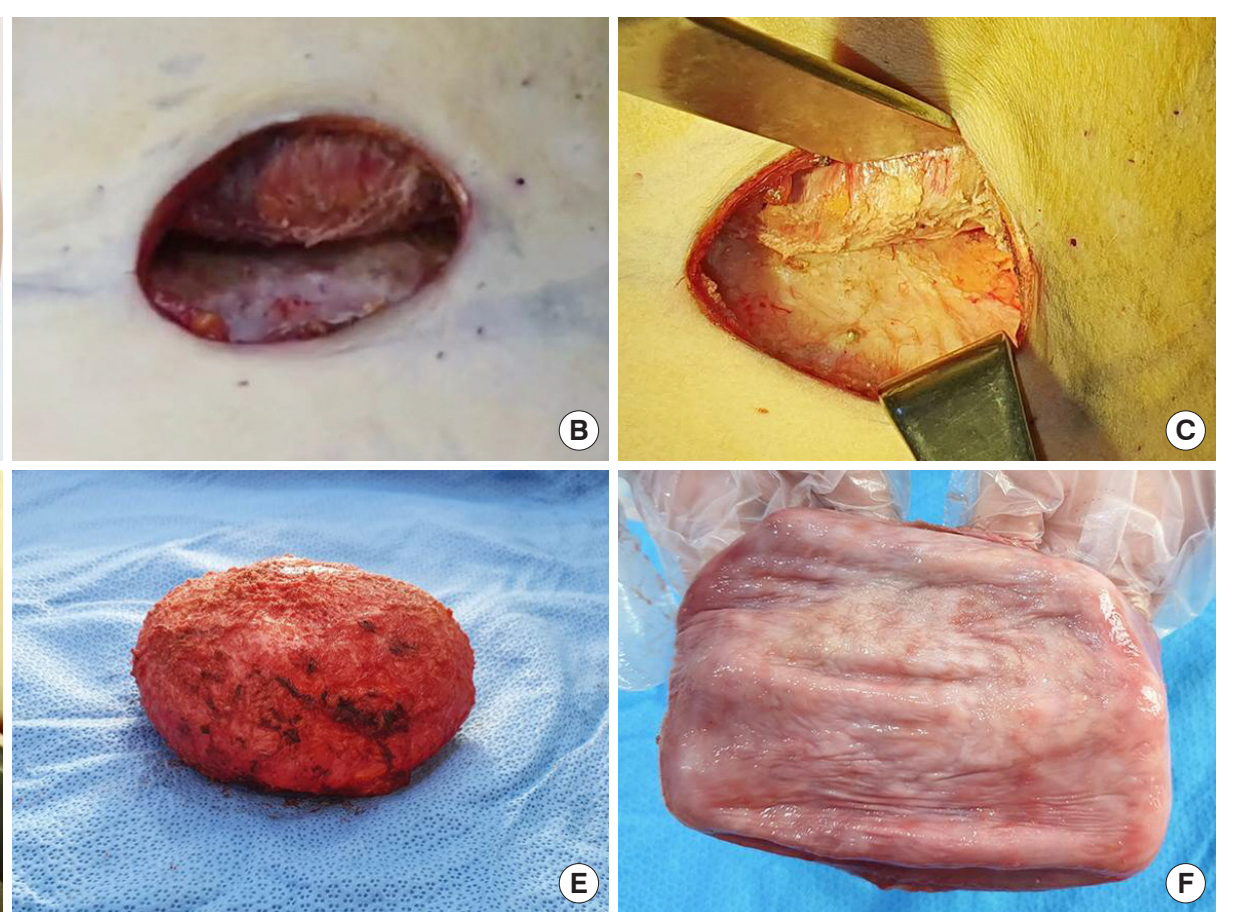

Fig. 6. A case involving an inframammary fold (IMF) incision. (A) Initial photograph presenting severe bottoming-out on the right breast and a bottom-up pattern with upward migration of the IMF line on the left breast. (B) Intraoperative photograph; dissection was done through the IMF incision. (C-E) A thick capsule was identified with focal calcifications, and en bloc capsulectomy was performed. (F) The thick capsule was removed. 
Table 3. Correlational analysis between variables

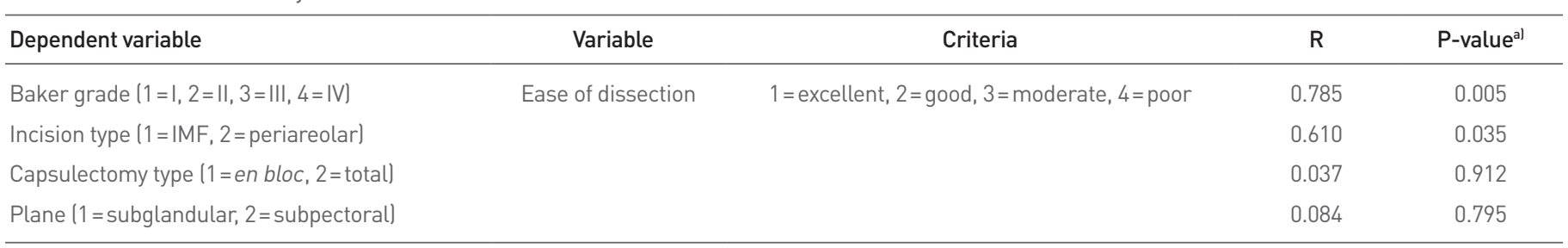

IMF, inframammary fold.

${ }^{\text {a) }}$ Statistically significant when $\mathrm{P}<0.05$.

tion was significantly higher in cases of Baker grade I or II capsular contracture $(\mathrm{P}=0.005)$. Furthermore, the ease of dissection was significantly higher for patients in the IMF incision group than for those in the periareolar incision group $(\mathrm{P}=0.035)$.

No other complications were noted within the follow-up period in any patients.

\section{Case 1}

A 36-year-old woman who underwent subpectoral breast augmentation with a smooth-type implant in 2012 visited our clinic in March 2019. She did not present with any complications; however, she was concerned about BIA-ALCL and wished to undergo explantation. She originally underwent axillary incision, but she preferred periareolar incision for reoperation because she did not want to undergo implant reinsertion. The surgeon also agreed with the choice of incision because total capsulectomy was planned to be performed without implant insertion. Dissection was performed easily (Fig. 4), there was a low bleeding tendency, and the scar length was $5 \mathrm{~cm}$ at follow-up (Fig. 5).

\section{Case 2}

A 41-year-old woman planned to undergo implant reinsertion in December 2018. She had been implanted with a tear-drop type implant in the subglandular plane through an IMF incision and underwent several reoperations because of capsular contracture, with Baker grade IV in the right breast. Because the patient requested reinsertion, en bloc capsulectomy was planned and the IMF approach was chosen. A better visual field was possible with this approach. However, dissection was difficult to perform because there were extensive adhesive tissue and inflammation reactions (Fig. 6). As the patient was lost to follow-up, we could not obtain follow-up images.

\section{DISCUSSION}

Various conditions such as hematoma, infection, seroma, and double capsule, can cause capsular contracture. Capsulectomy has been considered a suitable surgical treatment option. Slightly different surgical methods are used for total and en bloc capsulectomy. In general, total capsulectomy involves removal of the implant and the capsule separately, whereas en bloc capsulectomy involves removal of the implant while it is enclosed in a capsule. In total capsulectomy, the incision length can be reduced, the difficulty of surgery is lower than that of en bloc capsulectomy, and various incision methods can be used [17,18]. However, there is a high risk of biofilm exposure in cases of reoperation involving implant reinsertion, and the risk of metastasis is high in cases of BIA-ALCL [20]. Indications for this procedure include shape transformation, position correction, simple implant replacement, and reoperation of smooth implants $[13,14]$.

Another advantage of en bloc capsulectomy is that the likelihood of reoperation can be reduced by a treatment method suitable for BIA-ALCL [23]. The disadvantages are that the incision must be long, the incision location is limited mainly to the IMF, and the difficulty of the operation is greater than that of total capsulectomy. The indications for en bloc capsulectomy include capsular contracture, BIA-ALCL, and inflammation [20,23]. The incisions length in this study was longer in the en bloc group than in the total capsulectomy group, but it was not significantly different $(5.67 \mathrm{~cm}$ vs. 4.5 $\mathrm{cm}, \mathrm{P}=1.000$ ).

An interesting finding of this study was a proportional correlation between the Baker grade and the ease of dissection during surgery $(\mathrm{P}=0.005)$ (Table 3$)$. The relationship between the degree of adhesion formation in the plane and Baker grade has not been studied previously. The relationship identified between these two factors in this study provides motivation for further research, such as histopathological studies, to be conducted to clarify the scientific evidence.

In cases of subglandular pockets, total capsulectomy could be performed relatively easily. The use of the subglandular plane during surgery has been reported to result in a lower incidence of capsular contracture [24]. Subpectoral pockets were often used as the site for implantation previously. In the process of explantation after primary augmentation with a subpectoral pocket, dissection was difficult in two locations: the anterior capsule, because of adhesion between the capsule and the pectoralis major muscle, and the medial part of the posterior capsule, because of adhesion between the rib cage and the capsule. Therefore, care must be taken when dissecting in these locations. Although not significantly different, dissection was easier in the subglandular pocket than in the subpecto- 


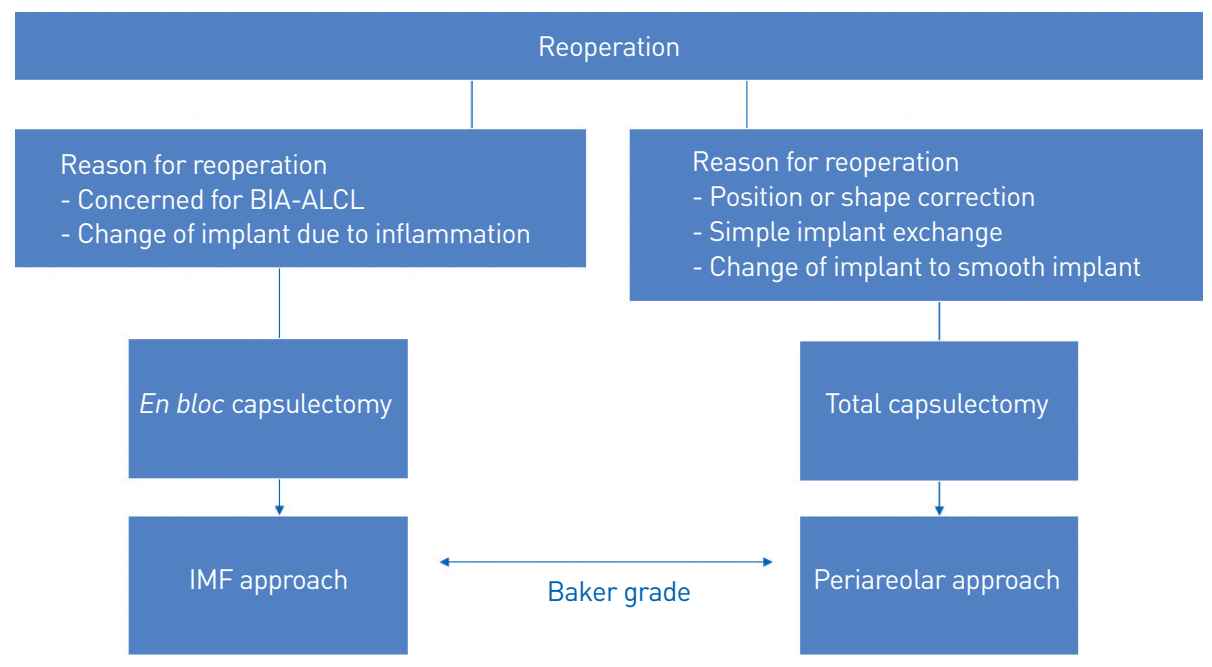

Fig. 7. Algorithm for selecting the incision type for total capsulectomy. BIA-ALCL, breast implant-associated anaplastic large cell lymphoma; IMF, inframammary fold.

ral pocket, depending on which breast pocket was used $(\mathrm{P}=0.6)$.

When a periareolar incision was made, the anterior capsule was relatively easy to dissect and the scar was inconspicuous. However, dissection of the posterior capsule was not easy, and it was difficult to remove the implant with en bloc capsulectomy. Therefore, there was also a risk of biofilm exposure due to the possibility of damage to the lactiferous duct during the incision process. For this reason, we did not prefer periareolar incisions unless patients requested them to conceal the scar. However, we found no significant difference in terms of the ease of dissection between posterior dissection via a periareolar incision and anterior dissection $(\mathrm{P}=0.53)$.

If an IMF incision was made, posterior capsule dissection was relatively easy and en bloc capsulectomy could be performed. We found no significant difference in the ease of dissection between anterior and posterior capsules $(\mathrm{P}=0.57)$. However, the disadvantage of this approach was that it left a longer scar $(\mathrm{P}=0.035)$. Moreover, it was also difficult to dissect the upper part beyond the top of the breast implant. Furthermore, there was a significant difference in the ease of posterior dissection between IMF and periareolar incisions $(\mathrm{P}=0.001)$.

When making the axillary incision, an endoscope was required. Dissection was easy for subglandular pockets, but en bloc capsulectomy was difficult due to the narrow entrance of the subglandular pockets. In subpectoral pockets, it was difficult to dissect the medial half of the posterior capsule, and there was a high likelihood of leaving the capsule on the bottom surface. For this reason, neither total capsulectomy nor en bloc capsulectomy was suitable.

Therefore, when en bloc capsulectomy is needed for preventive removal for BIA-ALCL and inflammation control, the IMF approach would be preferable, because it enables easy dissection and en bloc capsulectomy. A periareolar incision would be more desirable in terms of scar length unless en bloc capsulectomy is required in cases of position correction, shape deformity, and change of the implant type from textured to smooth. In addition, a lower Baker grade was associated with easier dissection. Based on these findings, an algorithm for choosing the incision type for total capsulectomy was suggested (Fig. 7).

The limitations of this study are its small population group and the fact that it was conducted through a retrospective chart review. The population was not selected homogeneously because the study was designed to analyze a retrospective cohort during a specific duration. Furthermore, the follow-up duration was too short to assess delayed complications, and the ease of dissection was subjectively evaluated only by the senior surgeon.

\section{NOTES}

\section{Conflict of interest}

No potential conflict of interest relevant to this article was reported.

\section{Ethical approval}

The study was approved by the Institutional Review Board of Soonchunhyang University Hospital (IRB No. 2020-13) and was performed in accordance with the principles of the Declaration of Helsinki.

\section{Patient consent}

The patients provided written informed consent for the publication and the use of their images.

\section{ORCID}

Tae Hyung Kim

Seok Min Yoon

Syeo Young Wee https://orcid.org/0000-0001-9537-2330 https://orcid.org/0000-0002-9780-814X https://orcid.org/0000-0002-1787-9715 
Hyok Sue Oh

Hyun Gyo Jeong

https://orcid.org/0000-0002-2802-3760

https://orcid.org/0000-0002-6378-6093

\section{REFERENCES}

1. Cunningham B. The Mentor core study on silicone MemoryGel breast implants. Plast Reconstr Surg 2007;120(7 Suppl 1):19S-29S.

2. Spear SL, Murphy DK, Slicton A, et al. Inamed silicone breast implant core study results at 6 years. Plast Reconstr Surg 2007;120(7 Suppl 1):8S-16S.

3. Spear SL, Seruya M, Clemens MW, et al. Acellular dermal matrix for the treatment and prevention of implant-associated breast deformities. Plast Reconstr Surg 2011;127:1047-58.

4. Centers for Devices and Radiological Health U.S. Food and Drug Administration (FDA). FDA update on the safety of silicone gel-filled breast implants [Internet]. Silver Spring, MD: FDA; c2011 [cited 2021 Mar 3]. Available from: http://www.fda.gov/downloads/MedicalDevices/ProductsandMedicalProcedures/ImplantsandProsthetics/ BreastImplants/UCM260090.pdf.

5. Pajkos A, Deva AK, Vickery K, et al. Detection of subclinical infection in significant breast implant capsules. Plast Reconstr Surg 2003;111: 1605-11.

6. Embrey M, Adams EE, Cunningham B, et al. A review of the literature on the etiology of capsular contracture and a pilot study to determine the outcome of capsular contracture interventions. Aesthetic Plast Surg 1999;23:197-206.

7. Cordeiro PG, McCarthy CM. A single surgeon's 12-year experience with tissue expander/implant breast reconstruction: part I. A prospective analysis of early complications. Plast Reconstr Surg 2006;118:82531.

8. Cordeiro PG, McCarthy CM. A single surgeon's 12-year experience with tissue expander/implant breast reconstruction: part II. An analysis of long-term complications, aesthetic outcomes, and patient satisfaction. Plast Reconstr Surg 2006;118:832-9.

9. McCarthy CM, Pusic AL, Disa JJ, et al. Unilateral postoperative chest wall radiotherapy in bilateral tissue expander/implant reconstruction patients: a prospective outcomes analysis. Plast Reconstr Surg 2005; 116:1642-7.

10. Evans GR, Schusterman MA, Kroll SS, et al. Reconstruction and the radiated breast: is there a role for implants? Plast Reconstr Surg 1995; 96:1111-5.
11. Kronowitz SJ, Robb GL. Radiation therapy and breast reconstruction: a critical review of the literature. Plast Reconstr Surg 2009;124:395-408.

12. El-Sheikh Y, Tutino R, Knight C, et al. Incidence of capsular contracture in silicone versus saline cosmetic augmentation mammoplasty: a meta-analysis. Can J Plast Surg 2008;16:211-5.

13. Wong CH, Samuel M, Tan BK, et al. Capsular contracture in subglandular breast augmentation with textured versus smooth breast implants: a systematic review. Plast Reconstr Surg 2006;118:1224-36.

14. Barnsley GP, Sigurdson LJ, Barnsley SE. Textured surface breast implants in the prevention of capsular contracture among breast augmentation patients: a meta-analysis of randomized controlled trials. Plast Reconstr Surg 2006;117:2182-90.

15. Gutowski KA, Mesna GT, Cunningham BL. Saline-filled breast implants: A Plastic Surgery Educational Foundation multicenter outcomes study. Plast Reconstr Surg 1997;100:1019-27.

16. Berry MG, Cucchiara V, Davies DM. Breast augmentation: part II. Adverse capsular contracture. J Plast Reconstr Aesthet Surg 2010;63: 2098-107.

17. Adams WP Jr. Capsular contracture: what is it? What causes it? How can it be prevented and managed? Clin Plast Surg 2009;36:119-26.

18. Pereira Leite L, Correia Sa I, Marques M. Etiopathogenesis and treatment of breast capsular contracture. Acta Med Port 2013;26:737-45.

19. Little G, Baker JL Jr. Results of closed compression capsulotomy for treatment of contracted breast implant capsules. Plast Reconstr Surg 1980;65:30-3.

20. Turton P, El-Sharkawi D, Lyburn I, et al. UK guidelines on the diagnosis and treatment of breast implant-associated anaplastic large cell lymphoma (BIA-ALCL) on behalf of the Medicines and Healthcare products Regulatory Agency (MHRA) Plastic, Reconstructive and Aesthetic Surgery Expert Advisory Group (PRASEAG). Eur J Surg Oncol 2021;47:199-210.

21. Maxwell GP, Gabriel A. Device considerations in breast augmentation. In: Neligan PC, Nahabedian MY, editors. Plastic surgery. 4th ed. New York: Elsevier; 2018. p. 47.

22. Ali Algadiem E, Aleisa AA, Alsubaie HI, et al. Blood loss estimation using gauze visual analogue. Trauma Mon 2016;21:e34131.

23. Swanson E. Evaluating the necessity of capsulectomy in cases of textured breast implant replacement. Ann Plast Surg 2020;85:691-8.

24. Headon H, Kasem A, Mokbel K. Capsular contracture after breast augmentation: an update for clinical practice. Arch Plast Surg 2015; 42:532-43. 